\title{
The Effect of a Stimulating Learning Environment on Pre-Service Teachers' Motivation and 21st Century Skills
}

\author{
Yonit Nissim ${ }^{1}$, Eyal Weissblueth ${ }^{1}$, Lennie Scott-Webber ${ }^{2} \&$ Shimon Amar $^{1}$ \\ ${ }^{1}$ School of Education, Ohalo Academic College, Qatzrin, Israel \\ ${ }^{2}$ Steelcase Education Solutions, Steelcase Inc. Grand Rapids, MI, USA \\ Correspondence: Eyal Weissblueth, School of Education, Ohalo Academic College, Qatzrin, 12900, Israel. Tel: \\ 972-4-682-5000. E-mail: eyalw@ohalo.ac.il
}

Received: March 8, 2016

doi:10.5539/jel.v5n3p29

\begin{abstract}
We investigated the effect of an innovative technology-supported learning environment on pre-service student teachers' motivation and 21st century skills. Students and instructors filled-in the Active Learning Post Occupancy Evaluation (AL-POE) questionnaire. Analysis included tests for individual items and a comparison of the overall mean, composite differences between pre- and post- occupation of the new classes. Over $80 \%$ reported high increase in creativity, motivation, ability to get higher grades and engagement in class while studying in the new learning environment. They gave significantly higher evaluations for practices and solutions in the new vs. traditional classrooms and perceived working there adequately and better, on many of the 21 st century skills. Therefore, learning environment plays an important role in preparing pre-service teachers.
\end{abstract}

Keywords: learning, environment, 21 st century skills, education, teaching

\section{Introduction}

\subsection{Theoretical Background}

A dynamic and constantly changing reality requires adaptation and change in educational approaches: the student is no longer to be seen as a passive receptacle for knowledge, but instead as an active participant in the construction of knowledge. This approach requires a substantial change in the learning process and it challenges the traditional hierarchical teacher-student relations. Recognition of the gap between modern and traditional approaches, together with the desire to reduce this gap, has led us to construct a program that created a more dynamic pedagogy within a space specially designed by Steelcase Inc.

This was a pioneering project, creating a novel combination of innovative pedagogy and appropriate learning environment design supported by different technologies. The program's main emphasis was on the development of different principles of thinking while using technological means to reinforce these principles of thinking "outside the box".

The term "learning environment" implies a potential place and space, such as a school, classroom, library, or any other possible place in which learning takes place. Although 21st century learning takes place in all these physical places, as we are in a period in which it is possible to learn through technological means, the learning environment can also be an on-line virtual environment that allows distance learning; or in other words, learning that does not depend on time or place. The 21 st century learning environment can be a process-supporting system that organizes a situation in which people learn optimally. These systems need to take account of the specific learning needs of each learner in order to support and promote the positive human relationships needed for an effective learning process. It is thus possible to differentiate between physical and socio-cultural spaces, and potentially also physical and virtual spaces. However, both are "learning enablers" or "facilitators" in a socio-cultural space.

Educators see the concept of a learning environment as a complex that defines the substance of teaching-learning and evaluation processes. This complex includes a number of factors: teacher, student, assignment, learning process, manner of learning, type of interaction between teacher and student, duration of learning, extent of heterogeneity of the learner group, etc. How these factors relate is influenced by teachers' educational world 
views concerning the meaning of the terms teaching, learning, and evaluation. These world views influence the character of the learning environment and the processes that take place within it.

For a learning environment to achieve its goals, there must be a dialogue between the physical and the educational dimension in the form of the environment. The physical design must meet the educational definition of a learning environment as well as the area of content that it is supposed to represent. The environment must allow a variety of teacher/instructor-student/researcher interactions by offering a variety of "changing situations" through which students can gain various different experiences. A learning environment should be flexible and dynamic so as to be adaptable to the changing needs of the teaching-learning-evaluation processes. This flexibility facilitates changes in the teacher-student interaction, and allows for the performance of various teaching-learning methods such as: learning in a plenary session, peer learning, group learning, etc. It is also important to provide easy access to required information for learners: a closed area with a book shelf will not serve 21st century learners well. Designers of a learning environment need to include up-to-date technological means that will allow individual learners, or groups of learners, to collaborate with others in the group and to conduct frequent dialogue with the teacher/instructor. An environment should be formed that creates learning "opportunities"; spaces that facilitate investigation, the posing of questions, and the allowing of the construction of knowledge and skills. The interaction between environmental design, educational learning, and physical design gives rise to "learning-oriented design". A recent study (Barrett \& Zhang, 2009) describe how learning environment influences student achievements and provide school architects with recommendations for students higher learning achievements.

Several studies (Elias et al., 1997; Maher \& Zins, 1987; Zins, Curtis, Graden, \& Ponti, 1988) dealt with the correlation between successful learning and various social-emotional aspects. They invested significant effort in improving the social and emotional development of children in school, arguing that academic success is based on social and emotional learning. They found that, when there was a clear framework, there was a positive correlation between social and emotional learning and academic success. Although these studies provided many examples of individual programs for social and emotional development, they did not present any synthesis of these programs. Neither was there any statistical evidence presented for the effectiveness of these programs.

\subsection{Research Design}

Relying on different theories concerning the connection between learning motivation and specially designed learning environments, our research aimed at analysing a concrete test case. We wanted to test the extent of influence of a new environment on academic success and motivation through responses to questionnaires completed by students. It should be noted that success in learning depends on a large number of variables: socio-economic status of the learner, internal motivation, and the design of the learning environment. Several studies have demonstrated that the construction of a purpose-built learning environment influences attention, motivation for learning, and academic achievement. In our study we examined the influence on student learning and motivation of a novel learning environment constructed by SES (Steelcase Educational Solutions).

To test levels of motivation, we defined "motivation" as: the extent to which individuals identify goals that are important to them, enlist resources, and cope with difficulties in order to effectively and rapidly attain those goals. Improvement in student motivation for learning is important, both for the teaching and learning of new knowledge or skills, since motivation will influence the manner in which teachers and students interact with learning materials (Hung, Chao, Lee, \& Chen, 2013). From the point of view of a teacher, student motivation to learn can influence their planning of teaching strategies for new classes so as to improve student learning performance (Keller, 1983). From the point of view of the student, deficient learning motivation means a higher risk of the new knowledge being constructed on defective grounds (Murphy \& Alexander, 2000). Many researchers agree that both teachers and students need technical skills to use computer applications, and that learning these skills can increase motivation to use computers in educational contexts. Some scholars also note that the effective use of internet applications can soften the boundaries between formal and informal learning (Bennett et al., 2012). Our particular focus was on indices that measure the implementation of 21 st century skills in the specially designed learning environment in relation to the following parameters: (a) Ability to be creative. (b) Motivation to attend class. (c) Ability to achieve a higher grade. (d) Engagement in class.

The focus was on responses to the following question: how did the specially designed learning environment, in comparison to the "old" traditional learning environment, influence learning according to the following parameters: collaboration, focus, active involvement, opportunity to be committed-involved, use of varied means, feedback in class, scenarios from daily reality, optimal learning methods, physical movement in space, stimulation, comfort for exercising (performance), and enriching experience? 
"Every society with an ancient tradition will resist technological changes" (Macionis, 1999). At first sight this is a logical and valid claim, suggesting that change in general, and in particular the introduction of technology, is associated with social alienation and assimilation difficulties. However, a fundamental difficulty arises from the conflict between tradition and innovation. This is evident in educational establishments that train kindergarten and school teachers by imparting values that contradict the viewpoints of traditional societies. However, many traditional societies are currently in a state of significant transition, influenced by the progress of "Western" societies, as exhibited through the different communication media, especially the Internet. This is a slow trend that is introducing viewpoints that often differ from, and sometimes completely contradict, the viewpoints of the traditional society that sanctions restricting traditions.

Some approaches describe the "intrusion" of technology into the traditional world as a threat. Barzilai-Nahon and Barzilai (2005) indicate areas in which religious and traditional communities see information and communication technologies as a threat. The Internet for example, stands in complete opposition to the hierarchical structure of a traditional society.

Economic factors also generate gaps between traditional and modern societies. Rogers (2003) noted that people in higher socio-economic groups adopt innovation more rapidly. There is a serious socio-economic gap between the Arab and Jewish communities in Israel. Arab society is considered as more conservative than Jewish society, and cultural factors may influence the extent of their openness to innovation. This means that the status of the kindergarten teacher as a socialization agent, imparting knowledge, values, and learning strategies for infants, becomes even more significant when the traditional Arab society is involved.

\subsection{Research Goals}

The current research aimed at examining the influence of an "innovative environment" at the college on the learning, motivation, and acquisition of 21 st century skills by teaching and education trainees. We hypothesized that a positive change would be found between the new learning environment and an improvement of student motivation to study and implement 21 st century learning skills.

\subsection{Research Questions}

(a) To what extent does a novel and specially-designed learning environment improve motivation to learn and to implement 21 st century skills?

(b) How do the teaching and education trainees perceive the influence of the novel learning environment on their learning in comparison to the influence of the familiar traditional classroom?

\section{Method}

\subsection{Research Population}

The research sample was composed of 113 student-teachers at a teacher-training college and was multicultural-characterized by various cultures, ethnic groups, and religions. However, most of the sample belonged to conservative and traditional groups. As can be seen in the socio-demographic statistics below, the sample was characterized by typical features of a multi-cultural society.

Forty instructors were approached on-line and asked to permit their students to answer the AL-POE questionnaire. Out of 113 students who agreed to participate, or who received the questionnaire, 87 completed it. The results presented in Table 1 summarize the respondents' characteristics in percentages of the research sample.

\subsection{Research Tools}

\subsubsection{Active Learning Post-Occupancy Evaluation (AL-POE) Questionnaire}

This questionnaire was described previously by Scott-Webber et al. (2013). It is divided into four sections that measure demographics, learning practices, solutions, and perceptions of outcomes. It allows a comparison between the quality and effects of traditional classrooms and of newer, innovative classrooms. It examines pedagogy and related learning settings using five key pedagogical approaches: delivering, applying, creating, communicating, and decision-making, and linking them to spatial learning settings.

\subsubsection{A New Learning Space}

College classrooms have a common, regular structure conforming to the conservative educational system. These classrooms are furnished with fixed seats, set out in rows and columns facing a regular blackboard. In recent

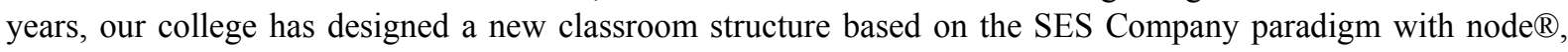
LearnLab ${ }^{\circledR}$, and media: scape ${ }^{\circledR}$. These facilities are equipped with the necessities for a new innovative learning 
space. The college has developed a new special class with media: scape ${ }^{\circledR}$ and other media solutions in order to assist in data acquisition and to provide discussion space. All spaces were separated by walls (Figure 1). The special environment fits a pedagogical model and is based on a dynamic and innovative approach.

Table 1. Research population characteristics

\begin{tabular}{|c|c|c|c|}
\hline General Characteristics & $\%(n=87)$ & General Characteristics & $\%(n=87)$ \\
\hline Gender & & Place of Residence & \\
\hline Women & $86 \%$ & City & $43 \%$ \\
\hline Men & $14 \%$ & Village & $25 \%$ \\
\hline College schools & & Settlement & $20 \%$ \\
\hline Education and Teaching & $66 \%$ & Kibbutz & $8 \%$ \\
\hline Physical Education & $19 \%$ & Development town & $4 \%$ \\
\hline Continued Education & $15 \%$ & Income Level & \\
\hline Year of study & & High & $2 \%$ \\
\hline Freshmen & $19 \%$ & High-Medium & $8 \%$ \\
\hline Sophomore & $33 \%$ & Medium & $75 \%$ \\
\hline Junior & $40 \%$ & Low & $15 \%$ \\
\hline Senior & $8 \%$ & Marital Status & \\
\hline Major & & Single & $51 \%$ \\
\hline Jewish studies & $6 \%$ & Married & $42 \%$ \\
\hline Early Education & $42 \%$ & Divorced & $5 \%$ \\
\hline Sciences & $19 \%$ & Widow & $1 \%$ \\
\hline English & $12 \%$ & Level of religious observance & \\
\hline Physical Education & $21 \%$ & Very religious & $4 \%$ \\
\hline Ethnic Origin & & Religious & $20 \%$ \\
\hline Ashkenazi Jews & $25 \%$ & Observant & $10 \%$ \\
\hline Sfardi Jews & $43 \%$ & Traditional & $33 \%$ \\
\hline Arab Muslim & $7 \%$ & Secular & $34 \%$ \\
\hline Arab Bedouin & $2 \%$ & & \\
\hline Arab Christian & $3 \%$ & & \\
\hline Druz & $18 \%$ & & \\
\hline Other & $3 \%$ & & \\
\hline
\end{tabular}

The pedagogical model that was developed, "Problem to Project Based Education", is based on a pedagogy that develops throughout the learning process at any time and in any place. This pedagogy is suited to the technological age and utilizes a variety of tools, spaces, and teaching aids in order to make learning an ongoing, experiential process. The learning process is based on a cyclical model of "dynamic learning", which is based on inspection and assessment.

Learning is interactive and progressive: interactive in the presentation of problems that are relevant to the topic of study, with the expectation of getting answers and solutions from the learners, engaging the learner in the research process, location, and mining of the relevant information with the help of digital online media; and progressive in so far as study will begin on an individual level and develop to the group level, a progressive, gradual transition taking place from individual study to peer study (in pairs, in groups of four, eight, etc.) up to the creation of a "learning community". According to this principle, each lesson begins with the proposal, 
location, or identification of a problem. Then begins the stage of finding the solution, the preparation, and the proposal of a plan of action based on project management and assessment.

\section{P2PBE - PROBLEM TO PROJECT BASED EDUCATION}

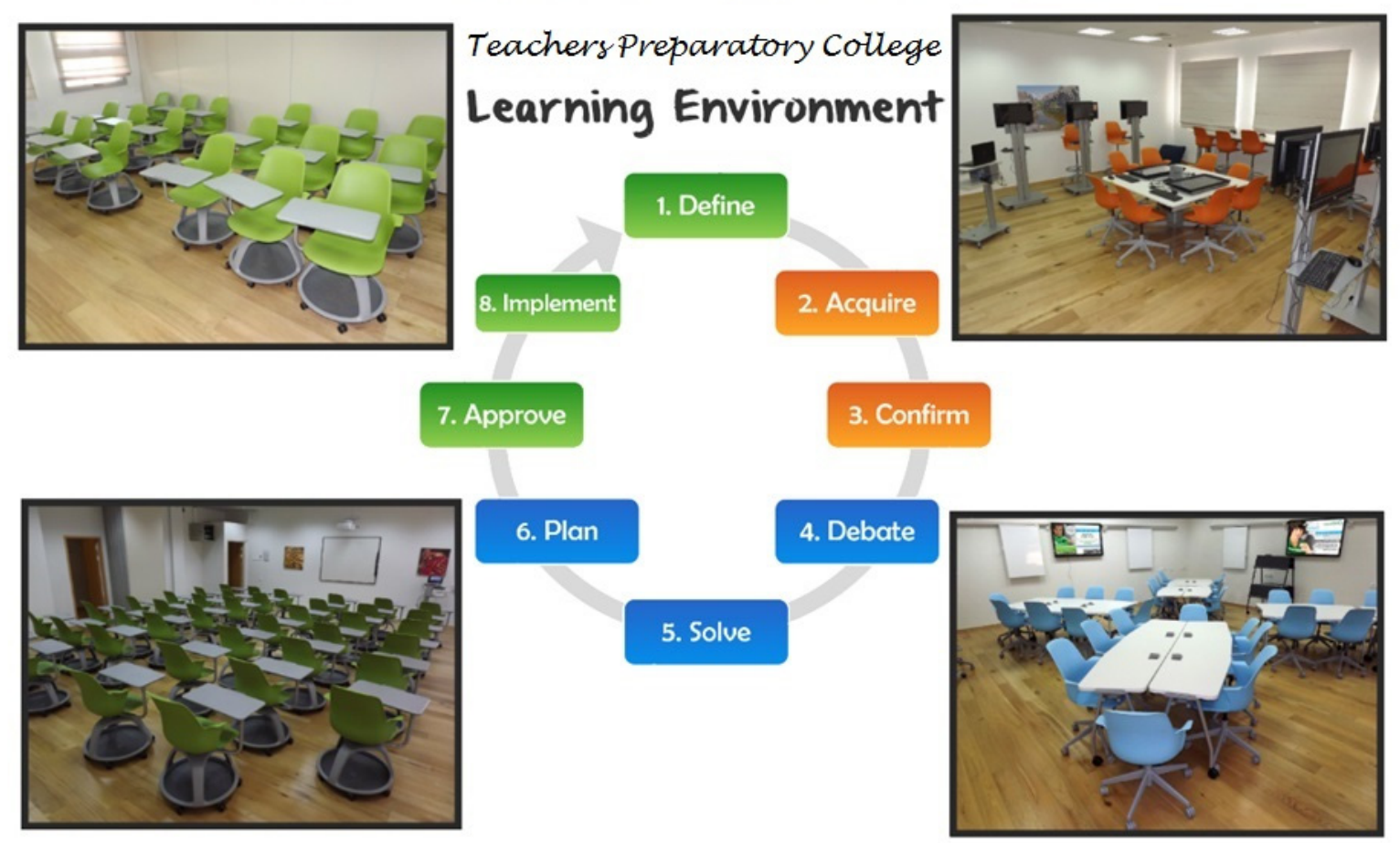

Figure 1. The new developed learning environment and its unique pedagogy

\subsection{Measured Variables}

The following abilities of student-teachers were measured by AL-POE questionnaire: creativity, motivation and engagement, and perception of their ability to achieve a higher grade. Students were asked to rate whether the experience in the "new" classroom helped to improve their creative ability, their motivation to attend class, their ability to achieve a higher grade, and their overall engagement.

\subsection{Process}

The AL-POE questionnaire was distributed online. All instructors who taught in the new learning environment were asked to allow their students to take the time to answer the questionnaire. However, both instructors and students were reminded individually to ensure that the AL-POE online was filled-in so as to increase the response rate. The questionnaire was administered twice during the academic year, at the beginning and end of semester.

\subsection{Data Analysis}

Responses to the questionnaire were analyzed with the help of the SAS software version 9.3. Wilcoxon signed rank tests were used for the individual item analysis, and given that there were 24 items, a Bonferroni-adjusted alpha level of $0.05 / 24$ was used. As this is about 0.002 , it was considered statistically significant for the individual items if a p-value was $<0.002$. To test the overall mean, composite differences between pre- and postpaired t-tests were calculated. The alpha level attained was 0.05 . Data were loaded into the SAS software. The data from the student responses contained 109 records, and after removing the records with more than 20 missing values, 90 records of useable student data remained. There were 24 records for the instructors' responses, and 15 contained usable data. 


\section{Results}

\subsection{Creativity, Motivation, Perceived Ability, and Engagement}

Students were asked to rate whether the experience in the "new" classroom helped them in their ability to be creative, their motivation to attend class, their ability to achieve a higher grade and their overall engagement. Results are given below in Figure 2.

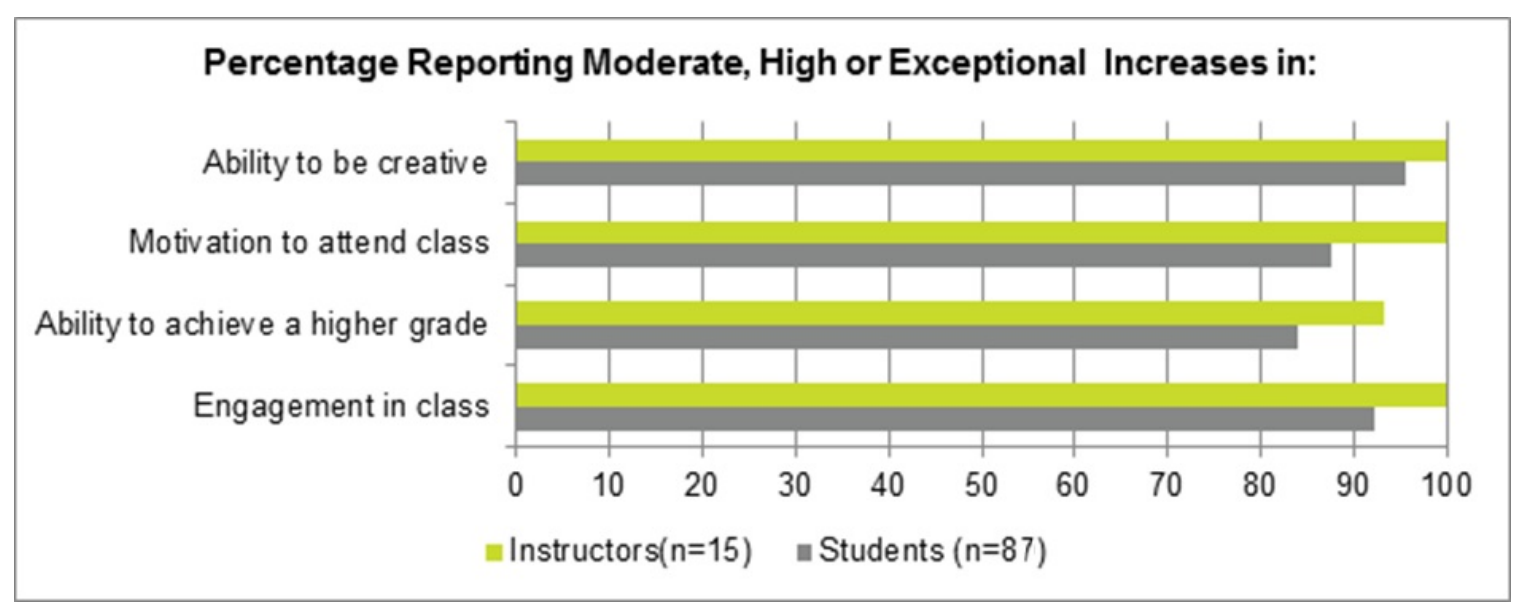

Figure 2. Percentages of students and instructors responders who reported "moderate, High or Exceptional" increase in creativity, motivation, perceived ability and engagement in the "new" classroom

Overall measures of engagement for each of the four measured parameters (ability to be creative, motivation to attend class, ability to achieve a higher grade, and engagement in class) were calculated for each student and instructor who responded to the majority of the questionnaire items. The overall scores were calculated by adding up responses for all items in the section relating to the particular dimension: for example, the grade for overall practices in the old traditional classrooms would be calculated by adding up scores for all twelve items relating to that environment, resulting in a possible maximum score of 48 and a possible minimum score of zero for each environment. Means of those scores are given in Figure 3.

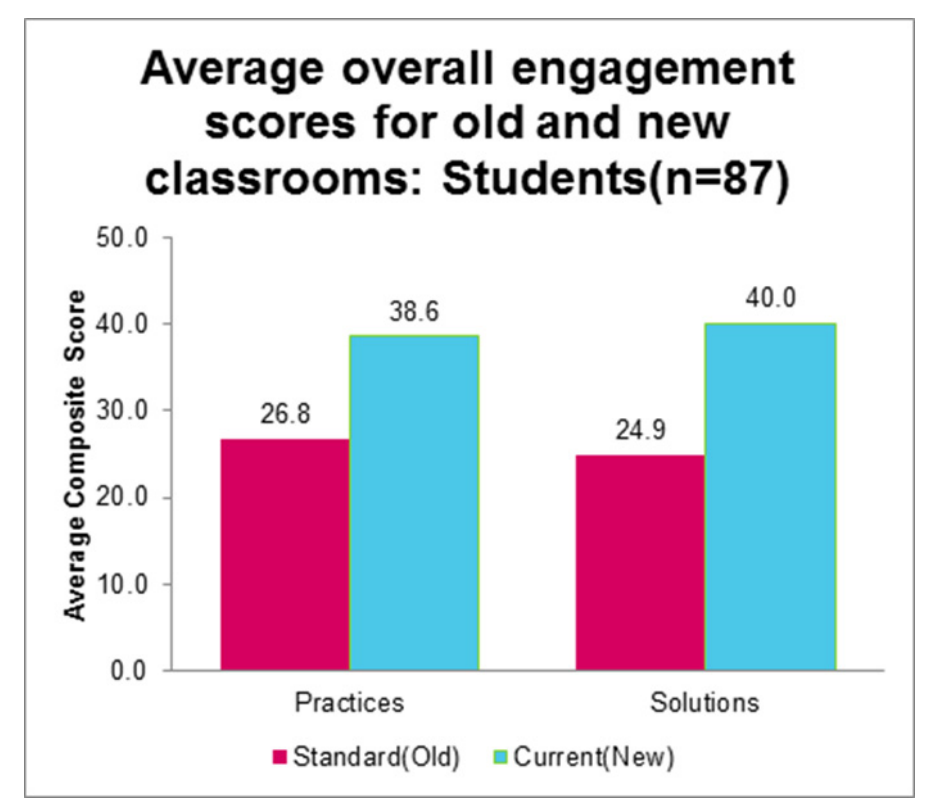

Figure 3. Average overall engagement scores of students for old and new classrooms 
A paired t-test was used to test if the means were significantly statistically different. For students, the average difference between the old and new environments was significantly statistically different from zero for both practices and solutions. The average difference in composite score was 12.0 units for practices with a p-value $<0.0001$ and 15.0 units for solutions with a p-value $<0.0001$. This represents improvements of one unit per item on average. When comparing student responses regarding their engagement with better pedagogical practices and solutions during classes held in the new classrooms with their engagement in traditional classes, see Figure 3, it was evident that students gave higher evaluations for practices and solutions in the new classrooms than in traditional classrooms (38.6 vs. 26.8 for practices and 40 vs. 24.9 for solutions respectively). This was also evident when comparing percentages of students who rated various factors involving practices and solutions in the new and in the old classrooms (Table 2). All average improvements in various factors for practices and solutions were found to be statistically significant.

Table 2. Percentage of students rating each factor as adequate in the old and in the new classroom, percentage of students rating the new classroom higher than the old, and average improvement in the new classroom $(n=87)$

\begin{tabular}{|c|c|c|c|c|}
\hline (a) Factor & Old Adequate & New Adequate & $\begin{array}{c}\text { Rated New } \\
\text { Higher }\end{array}$ & $\begin{array}{c}\text { Average } \\
\text { Improvement }\end{array}$ \\
\hline Collaboration * & $81 \%$ & $99 \%$ & $67 \%$ & 1.0 \\
\hline Focus * & $87 \%$ & $91 \%$ & $61 \%$ & 0.7 \\
\hline Active involvement * & $81 \%$ & $98 \%$ & $62 \%$ & 0.9 \\
\hline Opportunity to engage * & $91 \%$ & $98 \%$ & $58 \%$ & 0.9 \\
\hline Repeated exposure to material through multiple means * & $75 \%$ & $99 \%$ & $72 \%$ & 1.3 \\
\hline In-class feedback * & $81 \%$ & $97 \%$ & $56 \%$ & 0.9 \\
\hline Real-life scenarios * & $83 \%$ & $95 \%$ & $50 \%$ & 0.7 \\
\hline Ability to engage ways of learning best * & $76 \%$ & $92 \%$ & $60 \%$ & 0.9 \\
\hline Physical movement * & $53 \%$ & $99 \%$ & $74 \%$ & 1.7 \\
\hline Stimulation * & $65 \%$ & $93 \%$ & $71 \%$ & 1.2 \\
\hline Feeling comfortable to participate * & $88 \%$ & $99 \%$ & $51 \%$ & 0.7 \\
\hline Creation of enriching experience * & $78 \%$ & $96 \%$ & $68 \%$ & 1.1 \\
\hline (b) Factor & Old Adequate & New Adequate & $\begin{array}{c}\text { Rated New } \\
\text { Higher }\end{array}$ & $\begin{array}{c}\text { Average } \\
\text { Improvement }\end{array}$ \\
\hline Collaboration * & $82 \%$ & $99 \%$ & $72 \%$ & 1.1 \\
\hline Focus * & $81 \%$ & $96 \%$ & $63 \%$ & 0.8 \\
\hline Active involvement * & $82 \%$ & $99 \%$ & $75 \%$ & 1.2 \\
\hline Opportunity to engage * & $72 \%$ & $100 \%$ & $79 \%$ & 1.4 \\
\hline Repeated exposure to material through multiple means * & $75 \%$ & $98 \%$ & $75 \%$ & 1.4 \\
\hline In-class feedback * & $77 \%$ & $99 \%$ & $65 \%$ & 1.1 \\
\hline Real-life scenarios * & $69 \%$ & $98 \%$ & $71 \%$ & 1.2 \\
\hline Ability to engage ways of learning best * & $71 \%$ & $100 \%$ & $76 \%$ & 1.3 \\
\hline Physical movement * & $65 \%$ & $98 \%$ & $81 \%$ & 1.7 \\
\hline Stimulation * & $77 \%$ & $99 \%$ & $72 \%$ & 1.2 \\
\hline Feeling comfortable to participate * & $76 \%$ & $97 \%$ & $73 \%$ & 1.3 \\
\hline Creation of enriching experience * & $72 \%$ & $100 \%$ & $79 \%$ & 1.4 \\
\hline
\end{tabular}

\footnotetext{
* Significant statistical difference $\mathrm{p}<0.002$. (a) for pedagogical practices. (b) for pedagogical solutions.
} 
All differences between the old and the new classroom conditions were found to be significantly different from zero. Figure 4 presents the percentages of students who rated each factor as adequate, or better than adequate, in the "old" and "new" classrooms.

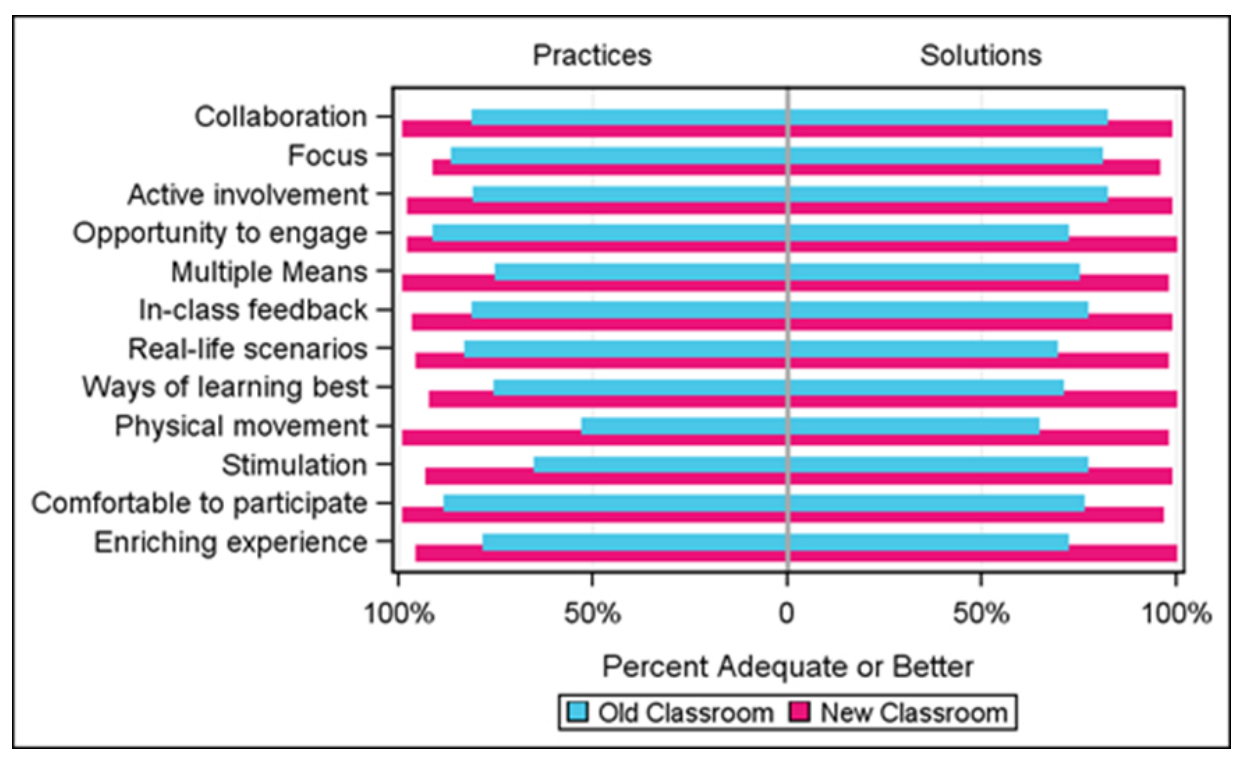

Figure 4. Percentages of students responders who rated each factor as adequate, or better than adequate, in the "old" and "new" classrooms

\section{Discussion}

The research aimed to examine and evaluate the extent of the influence of a "novel environment" on the learning, motivation, and acquisition of 21 st century skills by student-teachers studying the disciplines of education and teaching. The findings presented above indicate that a specially-designed environment, equipped with innovative technology, can significantly influence student perceptions of the extent of their motivation and commitment to learning, their creative skills, and the possibility that they will attain higher grades.

Two dimensions should be considered: firstly, each parameter (or skill) of those examined should be considered independently, including the relation to its significance for the acquisition of 21 st century education; and secondly, each parameter should be considered against the background of the comparison and gap between traditional and novel environments.

\subsection{Ability to Be Creative}

In this parameter we saw that students reported that the new learning environment increased their personal sense of ability to be creative. Creativity is a most significant skill which has been identified as an important educational skill for the modern era; it enables the individual to solve problems and to cope with learning in a creative manner. In a comparison between the traditional classroom and the innovative learning environment, we found that the new specially-designed environment enabled the use of state-of-the art technology and computerization, and thus empowered students to feel they were able to be more creative, as opposed to their feeling in the traditional out-dated classroom. This finding has significance for the learning process in general, as well as for teacher-training processes for future teachers.

\subsection{Motivation to Attend Class}

In recent decades, there has been a growing awareness of the central role motivation plays in student ability to succeed in learning and other information assimilation processes. These processes include: feelings towards learning and towards school, disruptive behaviour in the classroom, coping with difficulty and failure, and well-being in general (Pintrich \& Schunk, 1996). This recognition has stimulated theories and research programs that aimed at understanding the motivation and processes underlying student behaviour in school. An important goal of these theories and research studies was the ability to be effective in situations where student motivation is not optimal. Indeed, there have recently been several experiments and significant successes in implementing 
programs to encourage and promote student motivation in school (Weissblueth, Nissim, \& Amar, 2014; Assor, Alfi, Kaplan, Katz, \& Roth, 2000; Maehr \& Midgley, 1996). The findings presented above are most significant for the training of future teachers. We found that a specially designed, up-to-date, and computerized environment had empowering advantages for student motivation that was greater than the old-fashioned traditional classroom with the standard classroom structure.

\subsection{Ability to Achieve a Higher Grade}

Examination of the parameter relating to the students' sense of their ability to achieve a higher grade is connected to several skills that were previously presented. In different educational contexts, the students' academic achievements are influenced by personal factors such as cognitive ability, environmental factors such as the class climate, learning processes, and teacher-oriented factors and teaching methods (Chen, Hwang, Yeh, \& Lin, 2011). An appropriately designed computerized learning environment influences the class climate as a significant environmental characteristic. A meta-analysis (Wang, Hartel, \& Walberg, 1993) that reviewed 371 studies, with the aim of identifying the most significant influences on learning, found that affective-social and motivational factors of students in a broad age range had a far stronger and more meaningful influence on the learning processes and school achievements than the influence of peer group, school culture, teaching methods in class, and dozens of other factors, including: class management, teacher-student interaction, and emotional-motivational attributions and the peer group. Since our study only examined the influence of environmental aspects (design of a novel computerized space), we saw that this variable received a significant weight in preferring the new over the old traditional classroom environment. This implies that the learning environment, as an environmental characteristic, influenced the class climate as well as the students' sense of capacity for higher academic achievements.

\subsection{Engagement in Class}

Engagement in learning is a most significant multi-dimensional factor composed of several interrelated emotional factors (Appleton, Christenson, \& Furlong, 2008; Fredericks, Blumenfeld, \& Paris, 2004), based on cognitive and behavioural dimensions (Skinner, Furrer, Marchand, \& Kindermann, 2008). "Engagement" may be conceptualized as a variable that predicts or mediates a result in terms of academic achievement and other educational results. It is possible to see this variable as a major factor that in practice expresses the student's motivation to learn.

It can be seen from the above-said that all parameters studied are interrelated: they are all important in order to understand educational situations in the modern era. Moreover, the comparison between the modern futuristic environment and the classical traditional classroom, as represented in our findings, show that a specially-designed learning environment, adapted as appropriate for dynamic innovative learning and pedagogy suitable for the 21 st century, encourages creativity and improves motivation and learning ability, commitment to learning, and ambition to achieve better grades and higher evaluation. According to the responses, the gap between the traditional classroom and the innovative learning environment is large, and this has broad significance for pedagogy, education, and design. These findings are in line with the findings of other recent studies such as that of Scott-Weber et al. (2013).

\subsection{Traditional Society and Innovation}

The importance of these findings is amplified when considering that the research sample was mainly composed of people from traditional societies; that it, societies that do not usually rush to adopt new technologies and pedagogies. This aspect of our study also contributes to educational research among student-teachers: a significant difference was found in all the studied parameters, indicating an outstanding advantage for the new specially-designed computerized learning environment over the traditional classroom.

Thus, our study shows that it is possible to encourage the assimilation of change and progressive attitudes in a conservative traditional society using a program, where learning is constructed through collaborative instructor-teacher learning in an innovative learning space. Building on what is familiar, existing, and well known, it is possible to progress to new and advanced methods of teaching and learning. Dissipating fears, creating a supportive encouraging environment, and enabling interpersonal discourse, strengthened the students and allowed them to contribute to the learning and collaboration processes. Therefore, even individuals from traditional societies were able to adopt new skills that allowed them to maximize their abilities and fulfil their potential in the novel environment through the exploitation of their curiosity, encouraging and stimulating it and increasing motivation to learn. 


\subsection{Pedagogic Significance of the Findings}

In addition to the desirable characteristics of the traditional classroom, such as a supportive climate and respectful consideration of each student, the novel learning environment also included varied information technology and communications media that were continually being updated. These were used to attain educational goals and to improve teaching-learning-evaluation processes and their management. Technology provides significant advantages for pedagogy: e.g., the ability to investigate domains of knowledge that are not easily accessible, the enrichment of information resources, the mediation between concrete and abstract thinking through simulations and various games, improving the means and tools for the processing of information and the presentation of learning and knowledge. Technology can offer a greater variety of educational processes and experimentation by students and teachers. This shapes learning processes and promotes and assists teaching according to a knowledge construction approach. Research literature that deals with innovation in education sees the school learning environment as a very influential factor in the shaping innovation and its successful assimilation in the school.

A school, like any other organization, has reciprocal relations with its environment. It is influenced by its environment and influences it (Bar Haim, 2002). The environment may have an influence on both the content with which the school deals, and on the processes that take place within it. We therefore suggest that a solution for the adaptation of the education system to the needs of the 21 st century should be based on the following insights:

(1) There is a need to redesign the existing learning environment in teacher training and in elementary and secondary schools.

(2) An innovative learning environment has a significant influence on learner motivation, and it overcomes traditional-cultural conventions and paradigms.

(3) An innovative environment, reinforced with pedagogy supporting technology, can influence learner creativity by increasing engagement in learning processes and improving motivation and achievements.

The 21st century necessitates the design of a special learning environment that facilitates the acquisition of the skills that the education system would like to develop among its learners as part of their preparation for "real life" in a dynamic, rapidly changing, and uncertain environment. Throughout the world, educators, educational scholars, philosophers, opinion-makers, and laypeople have tried to come up with suitable pedagogic solutions for the modern era. Questions such as how to increase motivation and encourage commitment to learning have occupied the best of minds. We believe the present research to illuminate potential solutions that are supported by research relating to a large proportion of the core issues of innovative education, and that indicate possible directions for the future. Moreover, the significant processes highlighted here are extremely important for the training of future teachers in a changing world.

\section{References}

Appleton, J. J., Christenson, S. L., \& Furlong, M. J. (2008). Student engagement with school: Critical conceptual and methodological issues of the construct. Psychology in the Schools, 45(5), 369-386. http://dx.doi.org/10.1002/pits.20303

Assor, A., Alfi, O., Kaplan, H., Katz, L., \& Roth, G. (2000). The Autonomy-Relatedness-Competence (ARC) program: Goals, implementation principles, description and some results. Paper presented at the 7th workshop on achievement and task motivation. Leuven University, Belgium.

Bar Haim, A. (2002). Organizational behaviour (Vol. 1, No. 4, pp. 191-245). Israel: Open University.

Barrett, P., \& Zhang, Y. (2009). Optimal learning spaces: Design implications for primary schools (SCRI Research Report).

Barzilai-Nahon, K., \& Barzilai, G. (2005). Cultured technology: Internet and religious fundamentalism. The Information Society, 21(1), 25-40. http://dx.doi.org/10.1080/01972240590895892

Bennett, P. N., White, R. W., Chu, W., Dumais, S. T., Bailey, P., Borisyuk, F., \& Cui, X. (2012). Modeling the impact of short-and long-term behavior on search personalization. In Proceedings of the 35th international ACM SIGIR conference on Research and development in information retrieval (pp. 185-194). http://dx.doi.org/10.1145/2348283.2348312 
Chen, S. K., Hwang, F. M., Yeh, Y. C., \& Lin, S. S. (2011). Cognitive ability, academic achievement and academic self-concept: Extending the internal/external frame of reference model. The British Psychological Society.

Elias, M. J., Zins, J. E., Weissberg, R. P., Frey, K. S., Greenberg, M. T., Haynes, N. M., ... Schriver, T. P. (1997). Promoting social and emotional learning: Guidelines for educators. ASCD.

Fredericks, J. A., Blumenfeld, P. C., \& Paris, A. H. (2004). School engagement: Potential of the concept, state of the evidence. Review of Educational Research, 74, 59-109. http://dx.doi.org/10.3102/00346543074001059

Hung, I. C., Chao, K. J., Lee, L., \& Chen, N. S. (2013). Designing a robot teaching assistant for enhancing and sustaining learning motivation. Interactive Learning Environments, 21(2), 156-171. http://dx.doi.org/10.1080/10494820.2012.705855

Keller, J. M. (1983). Motivational design of instruction. In C. M. Regality (Ed.), Instructional design theories and models: An overview of their current status (pp. 386-434). Hillsdale, NJ: Lawrence Erlbaum.

Macionis, J. J. (1999). Sociology. New Jersy: Prentice Hall.

Maehr, M. L., \& Midgley, C. (1996). Transforming school cultures. Boulder, CO: Westview Press.

Maher, C. A., \& Zins, J. E. (1987). Psychoeducational interventions in the schools: Methods and procedures for enhancing student confidence. Oxford: Pergamon Press.

Murphy, K. L., \& Alexander, P. A. (2000). A motivated exploration of motivation terminology. Maryland, University of Maryland: University Press.

Pintrich, P., \& Schunk, D. (1996). Motivation in education: Theory, research \& applications. Englewood Cliffs, NJ: Prentice-Hall.

Rogers, E. M. (2003). Diffusion of innovations (5th ed.). New York: Free Press.

Scott-Webber, L., Strickland, A., \& Kapitula, L. R. (2013). Built environments impact behaviors: Results of an active learning post-occupancy evaluation. Planning for Higher Education Journal, 42(1).

Skinner, E., Furrer, C., Marchand, G., \& Kindermann, T. (2008). Engagement and disaffection in the classroom: Part of a larger motivational dynamic? Journal of Educational Psychology, 100(4), 765-781. http://dx.doi.org/10.1037/a0012840

Wang, M. C., Haertel, G. D., \& Walberg, H. J. (1993). Toward a knowledge base for school learning. Review of Educational Research, 63, 249-294. http://dx.doi.org/10.3102/00346543063003249

Weissblueth, E., Nissim, Y., \& Amar, S. (2014). Educating for the future: A structured course to train teachers for the 21st century. Creative Education, 5(11), 900912. http://dx.doi.org/10.4236/ce.2014.511103

Zins, J. E., Curtis, M. J., Graden, J. L., \& Ponti, C. R. (1988). Helping students succeed in the regular classroom: A guide for developing intervention assistance programs. San Francisco: Jossey-Bass.

\section{Copyrights}

Copyright for this article is retained by the author(s), with first publication rights granted to the journal.

This is an open-access article distributed under the terms and conditions of the Creative Commons Attribution license (http://creativecommons.org/licenses/by/3.0/). 